\title{
EQUALITY, THE CONSUMER PROTECTION ACT AND CUSTOMER-SEGMENT PRICING STRATEGIES: IS THERE RELIEF FOR THE POOR RICH TOURIST?
}

\section{Introduction}

The year 2010 is Soccer World Cup year in South Africa. From watching the press and other media it quickly becomes apparent that this event is perceived as something of a cash cow to be used (and sometimes even abused) to generate maximum profit for certain industries and its businesses. Complaints have been made about airlines and accommodation establishments hiking prices excessively. The tourism industry has been warned about the negative impact such exorbitant prices may have on tourism in the future as South Africa may no longer be considered as a value-for-money destination (eg, http://tourismupdate.co.za/print/NewsStory. aspx?newsld=21059 (accessed 2010-01-11); and Slabbert "Sakelui se Vraatsug Stook Sokkerpryse" 8 January 2009 Die Burger 13).

The hiking of prices is based on an anticipated increase in demand for certain services and products caused by the expected influx of soccer tourists. Businesses world-wide employ different pricing strategies to try and optimize revenue. One such pricing strategy that is employed is to differentiate between citizens and foreign nationals when charging for a service or product. This strategy in the context of the tourism industry is the focus of this note. Whilst the tourist is visiting South Africa s/he may want to visit some attractions and it is often at these places that an interesting situation can be observed. International tourists have to pay one price whereas citizens pay a reduced price. For instance, a visit to the website of the Addo Elephant National Park reveals that SANParks asks different prices - for South African citizens and residents R30 per day visit, SADC nationals R60 per day visit, and foreign visitors R130 per day visit to the Addo Elephant National Park (http://www.addoelephant.com/parks/addo/ tourism/tarifss.php accessed 2010-03-26). Similar price differentiation is employed by private businesses as well. Other jurisdictions in Africa also make use of similar customer-segment pricing strategies. The Ugandan Wildlife Authority differentiates between admission fees for foreign nonresidents and East-Africans to protected areas such as Lake Mburo and the Semuliki National Park (www.ugandawildlifeauthority.htm accessed 201004-05).

The Consumer Protection Act 68 of 2008 (hereinafter "the CPA"), once operational, will prohibit the charging of different prices for any goods or services to any persons or category of persons on the basis of one or more 
of the grounds of unfair discrimination contemplated in section 9 of the Constitution of the Republic of South Africa, 1996 (the Constitution) or Chapter 2 of the Promotion of Equality and the Prevention of Unfair Discrimination Act 4 of 2000 (hereinafter "the Equality Act"), amongst others. Does this mean that suppliers of services and products to tourists who differentiate in the prices asked between citizens and non-citizens will fall foul of this provision of the CPA? This is the question this note will endeavour to answer.

\section{Customer-segment pricing}

Businesses will often adapt the prices of a product or service to allow for differences in customers, products or locations. This means, for instance, that a business will sell a product or service at two or more different prices even though the difference in price is not based on any difference in the cost of providing the service or product (Kotler, Armstrong and Tait Principles of Marketing - Global and Southern African Perspectives (2010) 336).

Segmented pricing can take different forms and include, amongst others, location pricing, time pricing and customer-segment pricing. Location pricing is the strategy to ask different prices for different locations: a theatre would for instance ask different prices for tickets in different parts of the theatre. The cost of providing the product or service is the same for all the seats in the theatre but a premium can be asked for certain seats because of customer preference for those seats (location). Time-pricing, again, is the strategy where different prices are asked at different times of the year. Prices on airlines and travel and tourist packages may differ depending on the season.

For purposes of this note the focus is on customer-segment pricing, which is the strategy where different customers pay different prices for the same product or service (Kotler et al 336). An example would be where a movie theatre would ask a different price for children as for adults or when senior citizens are given a discount on purchases.

When a business asks different prices for the same product or service based on the citizenship of the customer it is a form of customer-segment pricing. The cost of delivering the product or service is no different from one customer to the next. The difference in price is based solely on the fact that the one is a citizen and the other a non-citizen.

\section{The importance of the tourism industry for South Africa}

Although the protection of the interests of vulnerable and historically disadvantaged groups as consumers probably served as the proximate cause for the introduction of the CPA, the Act recognizes the need to, amongst others, "protect the interests of all consumers" (emphasis added) and to "promote and protect the economic interests of consumers" (see the Preamble). Section 3 contains the purpose and policy of the Act and 
provides, amongst others, that the purposes of the Act are to promote and advance the social and economic welfare of consumers in South Africa by -

- establishing a legal framework for the achievement and maintenance of a consumer market that is fair and sustainable;

- promoting fair business practices;

- protecting consumers from unfair trade practice; and by

- promoting consumer confidence.

A tourist consumer market that is perceived to be fair and promoting fair business practices will promote consumer confidence and will contribute to the sustainability of the tourism industry in South Africa - an industry which is continually growing in importance for South Africa as a whole. It had been estimated that the contribution of tourism to the South African GDP in 1994 was no more than 2\% (The Department of Environmental Affairs and Tourism White Paper: The Development and Promotion of Tourism in South Africa (1996) 23). However, figures released by the South African Department of Trade and Industry in 2004 indicated a significant growth in the contribution of the travel and tourism industry to the GDP to the extent that the total (direct and indirect) contribution of tourism to the South African economy was estimated to be around R94 billion or 7\% of the GDP in 2004 (Department of Trade and Industry. Tourism in South Africa: Trends and Opportunities (2004) 2). In South Africa travel and tourism activity is expected to grow at a rate of $4.8 \%$ per annum in real terms between 2007 and 2016. This will mean an increase in the travel and tourism economic activity in South Africa from R198.1 billion in 2006 to R511.5 billion in 2016 which it is estimated will contribute $9.3 \%$ to the South African GDP (World Travel Tourism Council The 2006 Travel and Tourism Economic Research (2006) 6).

Of the main advantages of the travel and tourism industry are the ability of the industry to generate employment and to attract foreign currency (Vrancken "Introductory Perspectives on Travel Agency in South African Law" 2001 THRHR 64). Employment figures in the South African travel and tourism economy is expected to rise from an estimated 1083000 jobs in 2006 to 1500000 jobs (or one in every 11.6 jobs) in 2016. Furthermore, the tourism industry has the lowest ratio of investment to job creation, meaning that more jobs are created in this industry in comparison to any other per unit of capital invested. In South Africa, visitor exports (ie, foreign exchange being injected directly into the economy by inbound visitors) represent a very important contribution to the GDP. In 2006 travel and tourism was responsible for $13.9 \%$ (or R72.1 billion) of total exports, which is expected to increase to R204, 2 billion by 2016 (see World Travel Tourism Council The 2006 Travel and Tourism Economic Research (2006) 6).

From the aforementioned it is clear that the travel and tourism industry is an increasingly important part of the South African economy. Protecting the interests of the tourist consumer in South Africa is therefore of the greatest national concern. The CPA therefore has a critical role to play in ensuring 
also the protection of the consumers of tourism services and products in South Africa, both citizens and non-citizens. A consumer market which is perceived to be unfair, non-protecting of consumers and exploitative will not ensure a sustainable industry.

\section{Section 8(1)(e) of the CPA and the equality inquiry}

Asking different prices for the same product or service-based solely on the fact that the one person is a South African citizen and the other is a noncitizen appears to be a clear form of differentiation based on the ground of citizenship (or, from the perspective of the foreign tourist, non-citizenship). Is this form of differentiation legal?

Chapter 2 of the CPA sets out the fundamental consumer rights to be protected by the Act. The Act - once it has come fully into operation - will in terms of section $8(1)(e)$ require of suppliers of goods and services not to charge any persons or category different prices for goods or services unfairly. The relevant part of the section provides

"(1) Subject to section 9, a supplier of goods or services must not unfairly (e) charge different prices for any goods or services to any persons or category of persons;

on the basis of one or more grounds of unfair discrimination contemplated in section 9 of the Constitution or Chapter 2 of the Promotion of Equality and Prevention of Unfair Discrimination Act."

The wording of section 8(1) of the CPA places the question squarely in the ambit of a constitutional equality inquiry. Therefore the test formulated in Harksen $v$ Lane NO (1998 1 SA 300 (CC) par 53) should be applied to the problem (for a discussion of the Harksen test see amongst others Currie and De Waal The Bill of Rights Handbook (2005) 234-264; and Govindjee and Vrancken Introduction to Human Rights Law (2009) 74-80).

\section{- The first phase of the Harksen test}

In terms of the Harksen test the first matter to be considered is whether the legislation or conduct under consideration actually differentiates between people or categories of people. If it does not, then that is the end of the equality enquiry, but if there is differentiation, then the question is whether the differentiation bears a rational connection to a legitimate government purpose. This is the threshold-test - unless there is differentiation there can be no violation of the equality provisions. But, differentiation will only violate the equality provisions, particularly section $9(1)$ of the Constitution, if such differentiation does not have a rational connection to a legitimate government purpose.

So, is there differentiation in the problem under discussion? Different prices are asked of people on the basis of their citizenship. The price to be paid is determined by whether the person is a South African citizen or a non- 
citizen and therefore there appears to be clear differentiation on the basis of nationality or citizenship (for purposes of this note there is no legal difference between the concepts "nationality" and "citizenship" and the terms are therefore used interchangeably; and see Rautenbach and Malherbe Constitutional Law (2009) 57).

The "rational connection" test requires of the court to "evaluate the reasons given by the government for a law that differentiates to determine whether the purpose of the law is legitimate. It will then consider whether there is a rational relation between the purpose of the law and the differentiation imposed by the law" (Currie and De Waal 241). In Jooste $v$ Score Supermarkets Trading (Pty) Ltd (1999 2 SA 1 (CC)) the Court said "that the only purpose of rationality review is an inquiry into whether the differentiation is arbitrary or irrational, or manifests naked preference and it is irrelevant to this inquiry whether the scheme chosen by the legislature could be improved in one respect or another" (see also Prinsloo v Van der Linde 19973 SA 1012 (CC) par 25; and Geldenhuys v NDPP 20095 BCLR 435 (CC) par 33). This rationality test entails asking whether there is a good reason for treating people differently. If not, then people must be treated the same, in other words, formal equality, because inequality can arise from treating people differently that should be accorded equal treatment (Bonthuys and Albertyn Gender, Law and Justice (2005) 92).

Is there such a rational connection between the differentiation in the question under consideration and the government purpose to be achieved? What legitimate government purpose can be achieved by asking foreign visitors a higher price than nationals for the same service? Two possibilities come to mind. Firstly, the generation of more foreign exchange reserves by forcing the overseas visitor to spend more Rands, s/he has to spend more foreign currency. Certainly it can be argued that the generation of more foreign exchange is a legitimate government objective and, indeed, generating foreign exchange is one of the main benefits of tourism. Can this differential treatment of foreign tourists be considered rationally connected to this legitimate government objective? The necessary implication would be that a supplier of goods or services can charge just any price of a foreign tourist, especially for goods or services that are often the main or at least a contributory reason why the person has decided to visit South Africa by simply arguing s/he is helping the country to earn more foreign exchange. The potential for exploiting foreign tourists must be extremely worrying for the industry. The application of the differentiation is also arbitrary as not all foreign tourists are subject to differentiated pricing; some services or products are subjected to the differentiated pricing and others are not. Furthermore, the international tourist is often in a weak (unequal) bargaining position. If the tourist is in South Africa and wants to visit a certain attraction, s/he often only has a limited opportunity to do so. This reality is then exploited by charging a differentiated price.

Secondly, it could be argued that the differentiation is justified by the fact that the South African taxpayer maintains the national parks and should therefore receive a benefit when making use of these facilities. But why then 
must a foreign tourist pay more for this particular service or product? What about if $\mathrm{s} /$ he travels on SAA or drives on the roads or drink the water? This argument in favour of differentiated pricing makes the practice seem even more arbitrary. Of course this argument cannot be raised at all in respect of private businesses employing this type of customer-segment pricing strategy.

The negative impact that such differentiating practices can have on perceptions of tourists and ultimately the tourism industry cannot be in the best interest of South Africa. If the impact of the differentiation is to undermine the South African tourism industry ultimately then it cannot be said that there is a rational connection with a legitimate government purpose. It is therefore submitted that a challenge to this form of differentiation should fail at the first phase of the Harksen test.

A provision, decision or practice (such as a pricing strategy) which differentiates between people and which differentiation is not rationally connected to a legitimate government purpose violates the equality provisions of the Constitution as there is no rational reason for treating them differently. The limitation clause has the potential to justify this provision (Govindjee and Vrancken 77). It is difficult to see how a policy or provision that is arbitrary or irrational can be justifiable, even when attempting to serve a legitimate government purpose. However, the relevance, if any, of the limitation clause will be considered below.

\section{- The second phase of the Harksen test}

If it is found that charging foreign tourists a higher price than citizens is indeed rationally connected to a legitimate government purpose then it is required that the second phase of the Harksen test be considered. This phase of the test asks whether the differentiation amounts to unfair discrimination. A two-stage enquiry is used to answer this question. Firstly, does the differentiation constitute discrimination, and if so, secondly, is the discrimination unfair?

Not all differentiation constitutes discrimination: if the differentiation is based on one of the specified grounds mentioned in section 9(3) of the Constitution it is discrimination, and the unfairness of such discrimination is presumed. These grounds include race, gender, sex, pregnancy, marital status, ethnic or social origin, colour, sexual orientation, age, disability, religion, conscience, belief, culture, language and birth.

If the differentiation is based on an unspecified or analogous ground, then whether it is discrimination or not "will depend upon whether, objectively, the ground is based on attributes and characteristics which have the potential to impair the fundamental human dignity of persons as human beings or to affect them adversely in a comparably serious manner" (Harksen $v$ Lane supra par 53). Differentiation on nationality/citizenship (or rather differentiation on the basis of citizenship and non-citizenship) has been recognized as differentiation on a so-called analogous or unspecified ground 
(Larbi-Odam v MEC for Education (North-West Province) 19981 SA 745 (CC) par 19-20; and Govindjee and Vrancken 79).

It therefore appears as if, in the problem under discussion, there is discrimination. Is the discrimination unfair? As the discriminatory ground is an unspecified one the complainant must establish the unfairness thereof. Unfair discrimination essentially means that people are treated differently in a manner that impairs their fundamental dignity as human beings. Unfairness, in the final analysis, is determined by the impact of the discrimination on the complainants. This introduces the aspect of substantive equality requiring that, in considering whether there has been unfair discrimination, the approach should be contextual and historical (Bonthuys and Albertyn 98-99). Generally foreign tourists cannot be said to have suffered from past patterns of disadvantage, but what about the dignity of tourists confronted with this discriminatory practice? Unfair discrimination occurs when people are treated differently in a manner that is hurtful or demeaning (Currie and De Waal 244). (It would be informative to know the perceptions of foreign tourists about this specific example of customersegment pricing.) But can one seriously argue that it would not impact negatively on a person's dignity when s/he has to pay more for a product or service than others just because the person is an "outsider" or foreign visitor? Besides the economic impact, what is the message that is being conveyed? Does it not convey an idea of being different (perceived to be rich) and therefore less deserving of protection even and/or that "they" can be exploited as "they" are at our mercy? Is the reason for differentiation good enough? (Such a lack of a good reason for the differentiation must also be considered in the context of the rationality of the differentiation in relation to the government purpose. The absence of a good reason makes the differentiation arbitrary and irrational). It is therefore submitted that the discrimination under consideration is unfair. As the Constitutional Court stated in Pretoria City Council v Walker (1998 2 SA 363 (CC) par 81):

"No members of a racial group [different citizenship] should be made to feel that they are not deserving of equal 'concern, respect and consideration' and that the law is likely to be used against them more harshly than others who belong to other race groups [nationalities]."

\section{- The third phase of the Harksen test}

Once it has been determined that the discrimination is unfair it has to be considered whether the unfair discrimination is justified under section 36 of the Constitution, the limitations clause.

In terms of the said section the rights in the Bill of Rights can only be limited in terms of a law of general application to the extent that the limitation is reasonable and justifiable in an open and democratic society based on human dignity, equality and freedom, taking into account all relevant factors, including the nature of the right; the importance of the purpose of the limitation; the nature and extent of the limitation; the relation between the limitation and its purpose; and less restrictive means to achieve the purpose. 
The first question to be addressed in the limitation enquiry is whether the limitation is contained in a law of general application. Section 12(2)(ix) of the National Parks Act 57 of 1976 authorizes SANParks to determine, amongst others, admission prices to national parks. It states, amongst others, that the board (SANParks) may determine charges which are to be paid to enter or reside in a national park. Pricing strategy, as far as the national parks are concerned, is therefore a function exercised by SANParks in terms of legislation. However, the legislation does not permit or authorize unfair discrimination. The limitation of the foreign tourist's right to equality can therefore not be justified in terms of section 36(1) of the Constitution because it had not been authorized by any law. The limitation is not contained in a law of general application.

What about a private business making use of a customer-segment pricing strategy and differentiating on the basis of citizenship? The Constitutional Court in Barkhuizen v Napier (2007 5 SA 323 (CC) par 23) stated that a contractual term is not a law of general application and can therefore, on its own, not be subjected to a limitation analysis under section 36(1). The implication hereof is that a contract in terms of which a private supplier of goods or services to a non-South African tourist, which provides for a different price than for a South African citizen, cannot be justified in terms of the limitation clause if the contract violates the fundamental right (to equality) of the tourist.

It is therefore submitted that customer-segment pricing aimed at the tourist market and where the differentiation is based on citizenship cannot pass a constitutional challenge based on equality and this is indeed what the CPA wants to achieve.

\section{The Equality Act}

In terms of section 6 of the Equality Act neither the state nor any person may unfairly discriminate against any person. The Act, in section 1, defines discrimination as follows:

"Discrimination means any act or omission, including a policy, law, rule, practice, condition or situation which directly or indirectly -

(a) imposes burdens, obligations or disadvantage on; or

(b) withholds benefits, opportunities or advantages from,

any person on one or more of the prohibited grounds."

Prohibited grounds include the specified grounds as well as any other ground where discrimination based on that ground causes or perpetuates systemic disadvantage; undermines human dignity; or adversely affects the equal enjoyment of a person's rights and freedoms in a serious manner that is comparable to discrimination on a specified ground ( $\mathrm{s} 1$ of the Act). The Equality Act anticipates that new forms of discrimination may develop or be caused and wants to guard against it.

As indicated, nationality is not one of the specified grounds mentioned in section 9 of the Constitution, nor is it mentioned in section 1 of the Equality 
Act. However, nationality is one of the grounds to be given special consideration in terms of section 34 of the Equality Act for potential elevation to the status of one the listed prohibited grounds, thereby reflecting the sensitivity around differentiation on the basis of nationality or citizenship.

It is of interest to note that the Equality Act in section 24 imposes a general duty and responsibility on every person to promote equality and on the state a duty and responsibility to promote and achieve equality. Is the state, or a private business, fulfilling this duty if it differentiates between citizens and non-citizens in this manner in South Africa?

The Constitution creates a presumption of unfairness where the discrimination is based on one of the specified grounds, but the complainant bears the onus where the onus is based on an unspecified ground (s 9(5) of the Constitution). The Equality Act appears to provide a complainant with some procedural benefits over a constitutional challenge based on unfair discrimination. Section 13(1) of the Equality Act provides that if the complainant makes out a prima facie case of discrimination the respondent bears the onus of proof to show that the discrimination did not take place or that the conduct is not based on one or more of the prohibited grounds. Section 13(2) of the Act goes further than section 9(5) of the Constitution in that it creates a presumption of unfairness also in the case of discrimination on the basis of an unspecified (or analogous) ground such as nationality, provided the complainant establishes that the discrimination causes or perpetuates systemic disadvantage and/or undermines human dignity and/or adversely affects the equal enjoyment of a person's rights and freedoms in a serious manner that is comparable to discrimination on a specified ground. The complainant must still go some way in establishing unfairness (eg, establishing that the discrimination undermines human dignity).

In assessing whether the discrimination is fair or not section 14(2) and (3) of the Equality Act can assist. Section 14(2) provides that when considering whether the discrimination is fair certain aspects can be considered, such as whether the discrimination "reasonably and justifiably differentiates between persons according to objectively determinable criteria, intrinsic to the activity concerned" (s 14(2)(c)). Other factors may also be considered and include, amongst others, whether the discrimination impairs or is likely to impair human dignity; whether it has a legitimate purpose; whether and to what extent it achieves its purpose; whether there are less restrictive and less disadvantageous means to achieve the purpose, and, whether the respondent has taken the measure as being a reasonable step to accommodate diversity (s 14(3)).

The probability of a violation to the dignity of the foreign tourist was briefly considered above. The issue of a legitimate government purpose being served by the price differentiation was also mentioned. The mention of possible purposes does not mean there is one and/or that the actual purpose is a legitimate one. Whether it is achieving its purposes is therefore also an open question, but if the purpose is the increase in foreign reserves or subsidization of nationals then the arbitrary nature thereof mitigates against the measure achieving its purpose. Certainly there are more 
equitable ways of achieving this purpose which will be less restrictive and disadvantageous. It cannot also be argued that such a pricing strategy accommodates diversity.

\section{The CPA and the burden of proof}

\section{Section 10(2) of the CPA provides that}

"(1) In any proceedings contemplated in this Part -

(a) there is presumption that any differential treatment contemplated in section 8 is unfair discrimination, unless it is established that the discrimination is fair; and

(b) a court may draw an inference that a supplier has discriminated unfairly if -

(i) the supplier has done anything contemplated in section 8 with respect to a consumer in a manner that constituted differential treatment compared to that accorded to another consumer;

(ii) in the circumstances, the differential treatment appears to be based on a prohibited ground of discrimination; and

(iii) the supplier, when called upon to do so, has refused or failed to offer an alternative reasonable and justifiable explanation for the difference in treatment."

The CPA seems to go further than the Equality Act in that it creates a presumption of unfairness where any differential treatment contemplated in section 8 (of the CPA) takes place. Thus, differential treatment by charging different prices for any goods or services to any persons or category of persons on the basis of one or more grounds of unfair discrimination contemplated in section 9 of the Constitution or Chapter 2 of the Equality Act (prohibited grounds) creates a presumption of unfair discrimination entitling the consumer to protection against discriminatory marketing. The complainant therefore, it is submitted, has to establish only that there was an action within the ambit of section 8 (eg, customer-segment pricing) and that the differentiation was based on a prohibited ground as contemplated in the Equality Act, which includes also unspecified grounds such as nationality, for the presumption of unfairness to come into operation. The respondent then has the burden to show that the differentiation was fair.

To further assist the complainant (consumer) the CPA provides in section 10(2)(b)(i)-(iii) for certain scenarios, which, if they exist will allow a court to draw an inference of unfair discrimination from them. A few comments on these stated scenarios are called for.

The first scenario is difficult to distinguish from the substantive part of section $8(1)$ and seems to be an unnecessary repetition. If a consumer has established the differential treatment as contemplated under section 8 , then the court will make a finding of unfair discrimination. Section 10(2)(b)(i) does not assist the consumer any more than what section 8 already does.

The second scenario is also somewhat unclear as to how this will assist a consumer or the court. Differential treatment on a prohibited ground will still require a finding that the ground for differentiation is a prohibited ground. If the ground is specified the task is easier but if the ground is unspecified the 
consumer must establish and the court must still find that, objectively, the ground is based on attributes and characteristics which have the potential to impair the fundamental human dignity of persons as human beings or to affect them adversely in a comparably serious manner.

The only other possibility could reside in the use of the word "appears". Does this imply some lesser form of onus? Section 117 of the CPA requires as standard of proof in all matters regarding the Act being heard before the Tribunal or Consumer Court a balance of probabilities. Surely the consumer will have to establish a prima facie case that differentiation is based on a prohibited ground before the respondent will have to answer a case. It is submitted that this scenario will also not be of much assistance to a consumer or a court in establishing or finding that conduct contemplated in section 8 of the Act constitutes discrimination which is unfair.

The third scenario seems to allow a consumer to show that a supplier, when called upon to do so, refused or failed to offer a reasonable and justifiable explanation for the difference in treatment between the consumer and another. By doing this, the court can then draw an inference that the discrimination was unfair. Again the question must be asked what, if any, assistance this affords the consumer. Surely this will not prevent the respondent from supplying such reason during the court proceedings. The consumer will still have to make out a prima facie case to which the respondent can elect to respond or not. If the respondent does not respond to the prima facie case the court will find against him/her. The absence of a response when asked for same at any time earlier cannot lead to a finding against the supplier without a prima facie case made in court or before the Tribunal. So, again, the benefit to the consumer of this scenario is questionable.

Section 8 of the CPA is subject to the provisions of section 9. Section 9 provides reasonable grounds for differential treatment in certain circumstances, such as supplying goods or services at a discounted price solely on the basis that a minor has not yet attained a specified age or an adult who has attained a specified age of at least 60 years (s $9(1)(d))$. None of these is relevant to the question under discussion in this note.

\section{Conclusion}

The CPA was not primarily introduced to protect the foreign tourist visiting South Africa. This much is clear from the Preamble and Purpose Statement of the Act. However, the Act aims to protect the interests of all consumers also foreign tourists to South Africa.

In order to achieve this aim the CPA prohibits, amongst others, price differentiation between different consumers if the differentiation constitutes unfair discrimination. It has been argued that customer-segment pricing, where foreign tourists are asked a higher price for a service or product than South Africans, and where the price differential is determined solely on the ground of citizenship, falls foul of the CPA, the Equality Act and the Constitution. The main benefit that the CPA brings to the situation is that it 
makes it procedurally easier for a consumer to enforce his/her right to equality in the consumer market rather than making use of the Equality Act or a constitutional challenge. This is achieved through the creation of a presumption of unfair discrimination in section 10(2)(a) of the Act, which presumption is created by any discrimination on any prohibited ground which includes unspecified grounds such as nationality or citizenship.

It is probably unlikely that a foreign tourist will take the customer segmentpricing of SANParks or any other supplier for that matter to court, but maybe this is something for tourism-consumer protection groups to do. It is submitted that it will do more good for tourism and the country to have the same prices for all than to be considered exploiters of foreign tourists.

Mark Tait

and

Madéle Tait

Nelson Mandela Metropolitan University, Port Elizabeth 